\title{
ANALISA MODEL PROPAGASI OKUMURA- HATA DAN COST-HATA PADA KOMUNIKASI JARINGAN WIRELESS 4G LTE
}

\author{
Bengawan Alfaresi $^{1^{*}}$, M.Vierly Eltha Satya ${ }^{2}$, dan Feby Ardianto ${ }^{3}$ \\ ${ }^{1,2,3}$ Program Studi Teknik Elektro, Fakultas Teknik, Universitas Muhammadiyah Palembang \\ "Corresponding author, e-mail: begawan_alfarezi@um-palembang.ac.id
}

\begin{abstract}
Abstrak-Propagasi radio memilki peranan yang sangat penting dalam perkembangan jaringan telekomunikasi. Sinyal yang ditransmisikan oleh pengirim ke penerima mengalami redaman yang mengurangi kuat sinyal pada sisi penerima. Redaman yang terjadi pada saat perambatan gelombang di sebabkan oleh Large Scale Fading yang disebabkan oleh pengaruh benda dan bangunan yang ada disekitarnya. Penelitian ini bertujuan untuk membandingkan karakteristik path loss propagasi terhadap beberapa parameter yang ada pada sisi pengiriman maupun penerima serta membandingkan model propagasi large scale yang digunakan saat ini dalam jaringan LTE (Long Term Evolution). Simulasi dilakukan dengan dengan menggunakan Model propagasi OkumuraHata dan Cost-231 Hata serta menganalisa pengaruh path loss berdasarkan perubahan frekuensi, ketinggian BTS dan juga perbedaan karakteristik wilayah yaitu urban, sub-urban dan rural. Hasil dari penelitian menunjukkan bahwa pada pemodelan Okumura-Hata dan Cost-Hata mempunyai profil path loss yang hampir saya yaitu penggunaan frekuensi yang semakin tinggi, path loss yang dihasilkan semakin besar. Begitu juga dengan ketinggian antenna pemancar, semakin tinggi antenna pengirim maka path loss yang dihasilkan semakin kecil. Dari sisi karakteritik wilayah meunjukkan bahwa path loss yang dihasilkan pada daerah urban lebih tinggi dibandingkan dengan daerah sub-urban maupun rural area dikarenakan wilayah urban memiliki struktur bangunan yang lebih tinggi dan padat.
\end{abstract}

Kata Kunci : Path loss, Propagasi, Okumura, Hata, COST-231

\begin{abstract}
Radio propagation has a very important role in the development of telecommunications networks. The signal transmitted by the transmitter to the receiver experiences attenuation which reduces the signal strength at the signal received. Attenuation when wave propagation is caused by Large Scale Fading caused by the influence of objects and buildings that are around it. This study aims to compare the characteristics of propagation path loss against several parameters that exist on both transmitter and receiving sides as well as comparing the large scale propagation model currently used in the LTE (Long Term Evolution) network. Simulations are carried out using the Okumura-Hata propagation model and Cost-231 Hata and analyze the effect of path loss based on changes in frequency, antenna transmitter height, and also differences in regional characteristics such as urban, suburban and rural. The results of the study show that the Okumura-Hata and CostHata modeling has a path loss profile that is almost mine, namely the use of higher frequencies, the greater the resulting path loss. Likewise with the height of the transmitter antenna, the higher the sending antenna, the smaller the resulting path loss. In terms of regional characteristics, the path loss generated in urban areas is higher than in suburban and rural areas because urban areas have higher and denser building structures.
\end{abstract}

Keywords: Path loss, Propagation, Okumura, Hata, COST-231

\section{PENDAHULUAN}

Dalam beberapa tahun terakhir, komunikasi nirkabel seluler telah berkembang sangat pesat dan telah menjadikan ponsel seluler menjadi bagian yang penting dalam kehidupan masyarakat [1]. Pertumbuhan yang luar biasa ini meningkatkan kebutuhan alat network planning yang handal untuk mempercepat proses pengembangan jaringan telekomunikasi [2]. Kebutuhan pada jaringan berkualitas tinggi dan berkapasitas tinggi membutuhkan hasil prediksi coevrage yang cakupan akurat dan menjadi salah satu hal yang sangat penting. Oleh karena itu, 
untuk perencanaan coverage yang lebih akurat pada jaringan telekomunikasi, pengukuran kekuatan sinyal harus diperhatikan dalam perhitungan path loss propagasi.[3]

Model propagasi digunakan untuk memprediksi kekuatan sinyal yang diterima oleh receiver pada jarak tertentu terhadap pemancar. Model propagasi yang memprediksi kekuatan sinyal pada receiver dengan jarak pemisah tertentu antara pemancar-penerima (T-R) dan berguna dalam memprediksi area jangkauan radio pemancar. Model propagasi berguna untuk memprediksi redaman sinyal atau path loss [4]. Karakteristik propagasi radio bervariasi antara satu lingkungan ke lingkungan lainnya dan hal ini menunjukkan bahwa suatu Medan memilki karakteristik wilayah yang berda-beda. Dengan demikian, estimasi redaman yang akurat memainkan peran penting dalam perencanaan jaringan telekomunikasi. Keakuratan prediksi model propagasi juga tergantung pada kesesuaiannya suatu lingkungan.

Beberapa model propagasi radio untuk sistem komunikasi radio telah dikembangkan. Namun, pemilihan model yang paling cocok untuk wilayah geografis tertentu bukanlah tugas yang mudah, tetapi tergantung pada karaketristik medan dan serta efek dari bangunan yang sangat bervariasi dari satu tempat ke tempat lain [5]. Model propagasi dibagi menjadi dua kelompok; model empiris dan model deterministik. Model empiris yang didasarkan pada data pengukuran, sifat statistik dan beberapa parameter. Contoh kategori model ini adalah model Okumura-Hata maupun Cost-Hata. Model deterministik, ini adalah situs-spesifik, mereka memerlukan sejumlah besar informasi geometri tentang kota, laporan komputasi dan model yang lebih akurat [5].

Pada penelitian ini akan diteliti mengenai pengaruh parameter frekuensi, jarak dan tinggi BTS terhadap path loss propgasi pada teknologi 4G LTE-2100 dengan menggunakan metode OKUMURA-HATA dan metode COST 231 HATA. Pada penelitian ini menggunakan matlab sebagai media simulasi perhitungan dan penyajian datanya.

\section{TINJAUAN PUSTAKA}

\section{Path loss}

Path loss merupakan redaman atau daya yang hilang ketika pentransmisian sinyal dari pengirim ke penerima [6]. Pada kondisi LOS (Line of Sight), parameter yang mempengaruhi besarnya path loss pada ruang bebas yaitu frekuensi dan jarak antara pengirim dan penerima. Untuk kondisi yang N-LOS (Non-Line of Sight), parameter tinggi antenna pemancara, tinggi antenna penerima serta karakteristik wilayah juga mempengaruhi besarnya path loss. Model path loss statistik digunakan untuk memperkirakan kehilangan daya yang hilang dalam pengiriman gelombang radio dalam satuan $\mathrm{dB}$. Prediksi perhitungan pada kondisi LOS maupun medan dan lingkungan non-LOS dan pada umumnya menggunakan parameter lebih banyak dan lebih detail tergantung pada pemodelan yang digunakan [7].

\section{Model Propagasi Okumura-Hata}

Salah satu model propagasi yang paling umum untuk memprediksi loss sinyal dalam lingkungan sel makro yaitu model yang dikembangkan oleh Y. Okumura dan M. Hata yang didasarkan pada pengukuran di daerah perkotaan dan pinggiran kota. Rentang validitas model 
adalah frekuensi fc antara $150 \mathrm{MHz}$ sampai $1500 \mathrm{MHz}$, tinggi hb pemancar antara $3 \mathrm{~m}$ sampai $200 \mathrm{~m}$, tinggi $\mathrm{hm}$ pemerima antara $1 \mathrm{~m}$ sapai $10 \mathrm{~m}$ dan jarak antara pengirim dan penerima $(\mathrm{r})$ antara $1 \mathrm{~m}$ dan $10 \mathrm{~km}$ [8]. Rumus Okumura Hata dapat dirumuskan sebagai berikut [9]:

Urban:

$$
\begin{gathered}
\mathrm{Lu}(\mathrm{dB})=69,55+26,16 \log 10 \mathrm{fc}-13,82 \log 10 \text { hte }-\mathrm{a}(\mathrm{hre}) \\
+(44,9-6,55 \log 10 \text { hte } \log \log 10 d
\end{gathered}
$$

(1)

Sub Urban:

$\operatorname{Lsu}(\mathrm{dB})=\mathrm{Lu}-2\left\{\log 10\left(\frac{f c}{28}\right)\right\}^{2}-5,4$

Rural:

$$
\operatorname{Lr}(\mathrm{dB})=\mathrm{Lu}-4,78(\log 10 \mathrm{fc})^{2}+18,33 \log 10 \mathrm{fc}-40,9
$$

Untuk kota kecil dan menengah

$\mathrm{a}(\mathrm{hre})[\mathrm{dB}]=(1,1 \log 10 \mathrm{fc}-0,7)$ hre $-(1,56 \log \mathrm{fc}-0,8)$

(4)

Untuk kota besar

$\mathrm{a}(\mathrm{hre})[\mathrm{dB}]=\left(3,2(\log 10(11,75 \text { hre }))^{2}-4,97\right.$ untuk fc $\geq 400 \mathrm{MHz}$

dimana Lu adalah path loss untuk daerah urban; Lsu adalah path loss untuk daerah sub urban; Lr adalah path loss untuk daerah rural; fc adalah frekuensi carrier dalam $\mathrm{MHz}$; d adalah jarak dari base station $(\mathrm{km})$; hte adalah tinggi base station $(\mathrm{m})$; hre adalah tinggi mobile station / handphone $(\mathrm{m})$ dan a(hre) adalah factor koreksi untuk ketinggian antena mobile station $(\mathrm{dB})$.

\section{Model Propgasi COST231-Hata}

Karena kesederhanaan dan keandalan Okumura-Hata model, European Co-operative for Scientific and Technical research (COST) memperluas model ini untuk mencakup frekuensi hingga 2GHz. Model ini juga menyediakan faktor koreksi untuk estimasi pathloss di lingkungan yang berbeda (pedesaan, sub-perkotaan dan perkotaan) [10]. Model propagasi ini valid jika digunakan untuk range frekuensi antara $1500-2000 \mathrm{MHz}$ dan Semua faktor lain valid seperti yang didefinisikan dalam model Hata. Namun, model COST 231 Hata membutuhkan ketinggian antena stasiun pangkalan berada di atas atap yang berdekatan dengan stasiun pangkalan.[10] Rumus pathloss pada model propagasi cost 231 Hata ini adalah sebagai berikut:

$\operatorname{Lp}(\mathrm{dB})=$

$46,33+(44,9-6,55 \log 10 \mathrm{ht}) \log 10 \mathrm{~d}+33,9(\log 10 \mathrm{f})+\mathrm{cm}-$ $13,82 \log 10(\mathrm{hr})-\mathrm{a}(\mathrm{hr})$

(6)

Untuk area Uban : 


$$
\left.\mathrm{a}(\mathrm{hre})=3,2(\log 11,75 \mathrm{hr})^{2}\right)-4,97
$$

(7)

Untuk area Sub Urban dan Rural :

$$
\mathrm{a}(\mathrm{hre})=(1,1 \log \mathrm{f}-0,7) \mathrm{hr}-(1,56 \log \mathrm{f}-0,8)
$$

Dimana $\mathrm{f}$ adalah frekuensi dari $1500 \mathrm{MHz}$ sampai dengan $2000 \mathrm{MHz}$; ht adalah tinggi antena base station (m); hr adalah tinggi antena mobile station / Handphone (m); d adalah jarak antara base station dengan mobile station $(\mathrm{km})$; a(hre) adalah faktor koreksi untuk tinggi efektif antena; $\mathrm{cm}$ adalah $0 \mathrm{~dB}$ (untuk ukuran medium kota dan daerah sub urban) dan $\mathrm{cm}: 3 \mathrm{~dB}$ (untuk daerah pusat kota).

\section{METODE PENELITIAN}

Pada penelitian ini melalui beberapa tahapan penelitian yaitu tahap pertama analisa data awal yang merupakan studi literatur pada jurnal maupun buku yang berhubungan dengan propagasi gelombang radio. Kemudian tahap kedua persiapan alat dan bahan yaitu berupa hardware (laptop) maupun software (Matlab 2016). Tahapan ketiga yaitu proses perhitungan dan simulasi dengan menentukan parameter independent variable yang diamati. Tahapan terakhir yaitu melakukan analisa terhadap hasil simulasi.

\section{HASIL DAN PEMBAHASAN}

\section{Analisa Model Propagasi Okumura-Hata}

Model propagasi Okumura-Hata merupakan model empiris yang dalam kondisi N-LOS. Pada model propagasi Okumura-Hata terdapat beberapa parameter yang berpengaruh terhadap path loss yang dihasilkan yaitu frekuensi (f), jarak (d), ketinggian BTS (hb), ketinggian penerima (hr) dan juga karaketistik wilayah. Hasil simulasi path loss dengan perubahan frekuensi, ketinggian BTS dan karakteristik wilayah ditunjukkan pada gambar 2 berikut: 

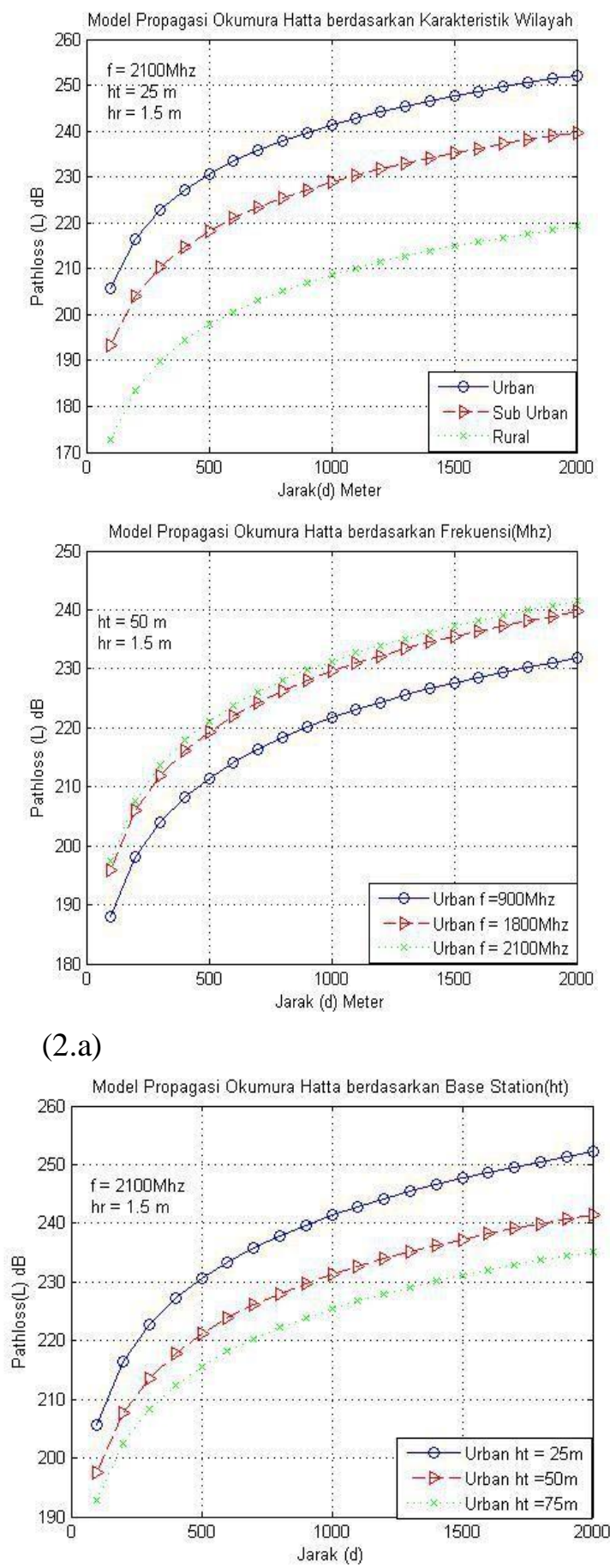

(2.c)

Gambar (2.a) Pathloss Okumura-Hata terhadap karakteristik wilayah (2.b) Pathloss OkumuraHata terhadap frekuensi (2.c) Pathloss Okumura-Hata terhadap tinggi BTS

Gambar 2.a menunjukkan besarnya path loss berdasarkan karakteristik wilayah urban, sub-urban serta rural dengan menggunakan frekuensi $2100 \mathrm{Mhz}$ dengan ketinggian antena base sttaion $25 \mathrm{~m}$ serta tingggi antena penerima $1.5 \mathrm{~m}$. Pada jarak antara transmitter dan receiver $1000 \mathrm{~m}$ pada wilayah urban akan menghasilkan pathloss sebesar $240 \mathrm{~dB}$, untuk wilayah suburban menghasilkan pathloss sebesar $230 \mathrm{~dB}$ dan untuk wilayah rural area akan menghasilkan patloss sebesar $210 \mathrm{~dB}$. Dari analisa tersebut menunjukkan bahwa path loss yang dihasilkan di 
daerah urban menghasilkan path loss yang paling besar. Hal ini dikarenakan pada wilayah urban didominasi oleh gedung dan bangunan yang ada di sekitarnya. Path loss yang dihasilkan pada wilayah rural area memilki besar path loss yang paling kecil. Hal ini dikarenakan dikarenakan pada wilayah rural area memilki sedikit halangan berupa bangunan yang ada di wilayah tersebut.

Pada gambar 2.b merupakan hasil simulasi Okumura-Hata berdasarkan perbedaan frekuensi carrier yang digunakan. Pada penelitian ini kita mensimulasikan menggunakan 3 frekuensi yang berbeda yaitu frekuensi $900 \mathrm{Mhz}$, frekuensi $1800 \mathrm{Mhz}$ dan frekuensi $2100 \mathrm{Mhz}$. Tinggi antena base (ht) diasumsikan $50 \mathrm{~m}$, serta tinggi antena penerima (hr) $=1.5 \mathrm{~m}$ dan jarak jangkauan $\mathrm{d}=0-2000 \mathrm{~m}(2 \mathrm{~km})$ dengan asumsi wilayah urban yang digunakan. Berdasarkan gambar tersebut pada jarak yang sama yaitu $2000 \mathrm{~m}$ dengan frekuensi frekuensi $900 \mathrm{Mhz}$ maka pathloss yang dihasilkan sebesar $232 \mathrm{~dB}$, sedangkan untuk frekuensi $1800 \mathrm{Mhz}$ pathloss yang dihasilkan $240 \mathrm{~dB}$, dan untuk frekuensi $2100 \mathrm{Mhz}$ path loss yang dihasilkan $242 \mathrm{~dB}$. Dari analisa tersebut menunjukkan bahwa semakin tingginya frekuensi yang digunakan maka path loss yang dihasilkan semakin besar.

Simulasi pada model propagasi Okumura-Hata yaitu seperti yang ditunjukkan pada gambar 2.c. Simulasi dengan menggunaan jarak antara pengirim (BTS) dan penerima yaitu 0$2000 \mathrm{~m}$, frekuensi yang digunakan yaitu $2100 \mathrm{Mhz}$ serta ketinggian pada antenna penerima yaitu $\mathrm{hr}=1.5 \mathrm{~m}$. Pada simulasi ini dengan menvariasikan ketinggian yaitu pada $\mathrm{ht}=25 \mathrm{~m}, \mathrm{ht}=$ $50 \mathrm{~m}$ dan ht=75 m. Path loss yang dihasilkan yaitu pada jarak yang sama yaitu $1000 \mathrm{~m}$ antara receiver dan transmitter, Untuk ketinggian BTS $25 \mathrm{~m}$ pathloss yang dihasilkan $241 \mathrm{~dB}$, sedangkan untuk ketinggian BTS 50 m pathloss yang dihasilkan $232 \mathrm{~dB}$ dan ketinggian BTS $75 \mathrm{~m}$, pathloss yang dihasilkan $225 \mathrm{~dB}$. Semakin tinggi bts (ht) yang terpasang aka pathloss yang dihasilkan semakain kecil. Hal ini dikarenakan semakin tinggi letak antenna pengirim maka rintangan dari lingkungan setempat pada wilayah tersebut semakin sedikit.

\section{Analisa Model Propagasi Cost 231-Hata.}

Pada simulasi dengan Model propagasi Cost-Hata dengan melakukan beberapa perubahan parameter yang berpengaruh terhadap path loss yang yaitu frekuensi (f), jarak (d), ketinggian BTS (hb) dan juga karaketistik wilayah. Hasil simulasi path loss dengan perubahan frekuensi, ketinggian BTS dan karakteristik wilayah ditunjukkan pada Gambar 3 berikut: 

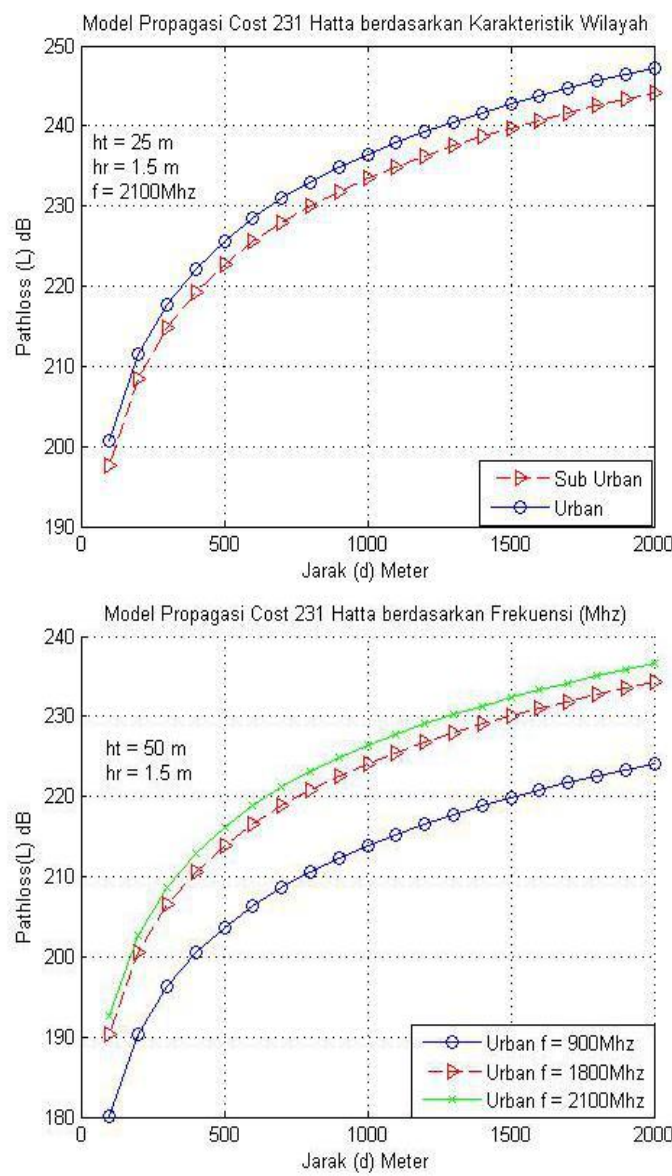

(3.a)

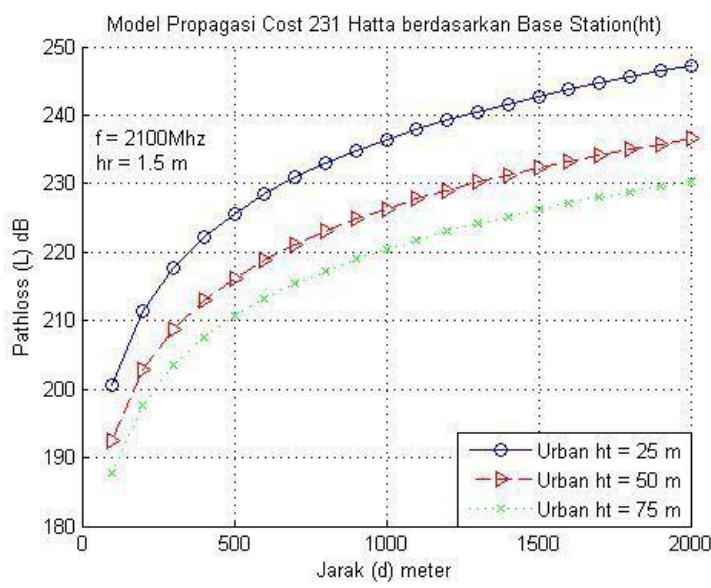

(3.c)

Gambar (3.a) Pathloss Cost231-Hata terhadap karakteristik wilayah (3.b) Pathloss Cost231-Hata terhadap frekuensi (3.c) Pathloss Cost231-Hata terhadap tinggi BTS

Gambar 3.a menunjukkan hasil simulasi pemodelan Cost-Hata terhadap perbedaan karakteristik wilayah. Simulasi dengan menggunakan asumsi jarak antara pengirim dan penerima (d) yaitu 0 - $2000 \mathrm{~m}$, dengan ketinggian BTS (ht) $25 \mathrm{~m}$ dan ketinggian mobile (hr) $=1.5 \mathrm{~m}$ serta frekuensi yang digunakan yaitu $2100 \mathrm{Mhz}$. Pada jarak yang sama yaitu $1000 \mathrm{~m}$ untuk perbedaan karakteristik wilayah pada daerah suburban pathloss yang dihasilkan sebesar 
$234 \mathrm{~dB}$ sedangkan untuk daerah urban, pathloss yang dihasilkan sebesar $237 \mathrm{~dB}$. Pada jarak yang sama $2000 \mathrm{~m}$ untuk daerah urban pathlos yang dihasilkan sebesar $245 \mathrm{~dB}$ sedangkan untuk daerah suburban pathloss yang dihasilkan $242 \mathrm{~dB}$. Hal ini dapat disimpulkan bahwa path loss yang dihasilkan pada daerah urban lebih besar dibandingkan dengan path loss pada daerah sub urban. Hasil dari model cost-hata memilki karakter path loss yang sama dengan okumura-hata.

Pada gambar 3.b merupakan hasil simulasi cost-hata berdasarkan perbedaan frekuensi yang digunakan dengan jarak simulasi yaitu 0-2000 m, tinggi penerima yang digunakan yaitu $1.5 \mathrm{~m}$ serta ketinggian base station (ht) yang digunakan $50 \mathrm{~m}$. Hasil simulasi tersebut menunjukkan bahwa pada penggunaan frekuensi $900 \mathrm{Mhz}$ menghasilkan pathloss sebesar 223 $\mathrm{dB}$, sedangkan pada frekuensi $1800 \mathrm{Mhz}$ menghasilkan path loss sebesar $233 \mathrm{~dB}$, dan pada frekuensi $2100 \mathrm{Mhz}$, path loss yang dihasilkan sebesar $236 \mathrm{~dB}$. Dengan demikian semakin tinggi frekuensi yang digunakan menghasilkan pathloss yang semakin besar seperti pada model Okumura-Hata.

Hasil simulasi pada pemodelan propagasi Cost-Hata dengan mengamati perubahan ketinggian antenna pemancara yaitu dengan jarak yang sama yaitu $2000 \mathrm{~m}$, posisi ketinggian antenna pada $25 \mathrm{~m}$ menghasilkan path loss sebesar $248 \mathrm{~dB}$. Pada ketinggian antenna pemancar sebesar $50 \mathrm{~m}$, pathloss yang dihasilkan sebesar $235 \mathrm{~dB}$, serta pada ketinggian antenna $75 \mathrm{~m}$, pathlossnya yang dihasilkan sebesar $230 \mathrm{~dB}$. Dengan demikian semakin tinggi bts yang terpasang semakin rendah pathloss yang dihasilkan.

\section{Perbandingan Model Propagasi Okumura-Hata dan Cost 231-Hata terhadap perbedaan Karakteristik Wilayah}

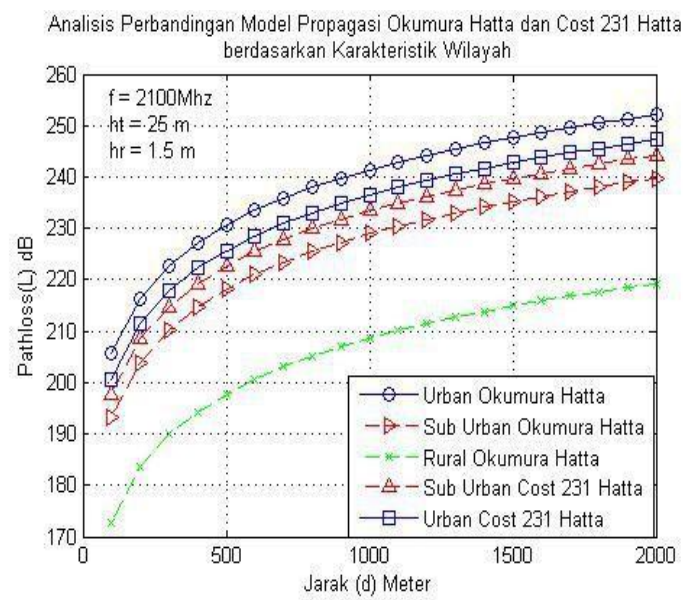

Gambar 4 Perbandingan Model Propagasi Okumura Hata dan Cost-Hata terhadap perbedaan Karakteristik Wilayah

Gambar 4 menunjukkan perbandingan model Okumura-Hata dan Cost-Hata terhadap perbedaan karakteristik wilayah. Pada pemodelan Okumura-Hata pembagian karakteristik wilayah dibagi menjadi 3 yaitu urban, sub-urban dan rural sedangkan pada pemodelan dengan menggunakan Cost-Hata dibagi menjadi 2 yaitu sub-urban dan urban area. Pada daerah urban, propagasi model Okumura-Hata memiliki pathloss yang lebih tinggi yaitu $252 \mathrm{~dB}$ dari model propagasi Cost-Hata yaitu sebesar $245 \mathrm{~dB}$. Sedangkan untuk daerah sub urban, pemodelan 
Okumura-Hata memiliki pathloss yang lebih rendah yaitu sebesar $240 \mathrm{~dB}$ dibandingkan dengan model propagasi Cost-Hata dengan pathloss yang dihasilkan $242 \mathrm{~dB}$. Profil path loss pada daerah rural area dengan pemodelan Okumura-Hata mempunyai hasil path loss yang paling rendah dibandingkan dengan karakteristik wilayah yang lain.

\section{KESIMPULAN}

Pada pemodelan Okumura-Hata dan Cost-Hata mempunyai profil path loss yang hampir saya yaitu penggunaan frekuensi yang semakin tinggi, menghasilkan path loss yang semakin besar. Begitu juga dengan ketinggian antenna pemancar, semakin tinggi antenna pemancar pada pengirim maka menghasilkan path loss yang semakin kecil. Dari sisi karakteritik wilayah meunjukkan bahwa path loss yang dihasilkan pada daerah urban lebih tinggi dibandingkan dengan daerah sub-urban maupun rural area dikarenakan wilayah urban memiliki struktur bangunan yang lebih tinggi dan padat. Perbandingan antara Okumura-Hata dan Cost-Hata menunjukkan bahwa pada daerah Urban, model Okumura-Hata memiliki pathloss yang lebih tinggi dibandingkan dengan Cost-Hata, sedangkan pada daerah Sub-Urban, pemodelan Okumura-Hata memiliki pathloss yang lebih rendah dibandingkan Cost-Hata.

\section{DAFTAR PUSTAKA}

[1] H. K. Hoomod, I. Al-Mejibli, and A. I. Jabboory, "Analyzing Study of Path loss Propagation Models in Wireless Communications at 0.8 GHz," J. Phys. Conf. Ser., vol. 1003, no. 1, pp. 1-8, 2018, doi: 10.1088/1742-6596/1003/1/012028.

[2] O. F. Oseni, S. I. Popoola, R. O. Abolade, and O. A. Adegbola, "Comparative Analysis of Received Signal Strength Prediction Models for Radio Network Planning of GSM 900 MHz in Ilorin, Nigeria," Int. J. Innov. Technol. Explor. Eng., no. 3, pp. 2278-3075, 2014.

[3] Z. Nadir and M. I. Ahmad, "Pathloss determination using Okumura-Hata model and cubic regression for missing data for Oman," in Proceedings of the International MultiConference of Engineers and Computer Scientists 2010, IMECS 2010, 2010, vol. II, no. 1, pp. 804-807.

[4] K. O. Kadiri and O. A. Somoye, "Computer Simulation of Path Loss Characterization of a Wireless Propagation Model in Kwara State , Nigeria," Int. J. Comput. Inf. Technol., vol. 3, no. 3, pp. 610-615, 2014.

[5] A. Ekeocha, N. Onyebuchi, and A. Ifenyinwa, "Comparative Study of Path Loss Models for Wireless Communication in Urban and Sub-urban Environment for Port Harcourt, Nigeria," Am. J. Eng. Res., vol. 4, no. 11, pp. 109-115, 2015.

[6] B. Alfaresi, T. Barlian, F. Ardianto, and M. Hurairah, "Path Loss Propagation Evaluation and Modelling based ECC-Model in Lowland Area on $1800 \mathrm{MHz}$ Frequency," J. Robot. Control, vol. 1, no. 5, pp. 167-172, 2020, doi: 10.18196/jrc.1534.

[7] O. Shoewu, S. O. Olatinwo, and D. D. Olatinwo, "Comparative Analysis of Pathloss in Metropolitan Domain in Nigeria using Okumura-Hata Model," Eur. J. Sci. Res., vol. 141, no. 1, pp. 5-15, 2016.

[8] O. P. Omolaye, G. A. Igwue, and G. A. Akpakwu, "OKUMURA-HATA : A PERFECT MODEL FOR DRIVING ROUTE UHF INVESTIGATION,” Am. J. Eng. Res. ( AJER ), vol. 4, no. 9, pp. 139-147, 2015.

[9] B. Alfaresi, "Analisa Indikator Performansi Jaringan 4G LTE (Long Term Evolution) Frekuensi $1800 \mathrm{MHz}$ terhadap Perubahan Jarak e-NodeB di Daerah Urban," J. Surya Energi, vol. 1, no. 2, pp. 60-70, 2017.

[10] O. I. Adu, F. E. Idachaba, and A. A. Alatishe, "Refarming $1800 \mathrm{MHz}$ GSM spectrum to LTE: He effects on coverage based on pathloss estimation," Lect. Notes Eng. Comput. Sci., vol. 1, pp. 673-676, 2014. 